\title{
Dexmedetomidine as an adjuvant to epidural 0.75\% ropivacaine in patients undergoing infraumbilical surgery: a clinical study
}

\author{
Bhawana Rastogi*, VP singh, Deepti Mangla, Kumkum gupta, Manish jain and MN Pandey \\ Department of Anaesthesiology \& critical care in NSCB Subharti Medical College, Meerut (UP), India
}

\begin{abstract}
Background: Epidural block provides surgical anesthesia as well as post-operative analgesia in patients undergoing lower abdominal surgeries. Ropivacaine, is safe and effective for regional anesthetic techniques. Dexmedetomidine, alpha- 2 agonist, as adjuvant to local anesthetic is reported to have synergistic effect for epidural anesthesia. The present study was designed with the aim to evaluate the efficacy and safety of dexmedetomidine as an adjuvant to epidural $0.75 \%$ ropivacaine in patients undergoing infraumbilical surgery.

Method: Eighty adult consented patients 18-58 yr of age, of either sex, of ASA grade I/II undergoing infraumbilical surgeries were enrolled for the present study. Patients were randomised in two groups of 40 patients each: Group A received epidural ropivacaine only whereas Group B received epidural ropivacaine and dexmedetomidine. Patients of group A received $15 \mathrm{ml} 0.75 \%$ ropivacaine $+1 \mathrm{ml}$ Normal Saline and group B received $15 \mathrm{ml} 0.75 \% \mathrm{ropivacaine}+0.6 \mu \mathrm{kg}^{-1}$ dexmedetomidine in $1 \mathrm{ml} \mathrm{NS}$ (group B) epidurally. Various block characterstics sensory onset time, time to complete motor block, time to two dermatome regression, duration of sensory analgesia and motor block, sedation scores, hemodynamic changes and any side effect were all recorded and statistically analysed by one way ANOVA and chi-square test. The $\mathrm{p}$ value $<0.05$ is considered significant and $\mathrm{p}<0.001$ as highly significant.

Results: The demographic profile of patients was comparable in both the groups. Onset of sensory block $(2.50 \pm 0.877$ vs $7.00 \pm 1.198$ min $)$ and establishment of complete motor blockade $(17.20 \pm 4.10$ vs $23.90 \pm 3.57 \mathrm{~min})$ was significantly earlier in the ropivacaine with dexmedetomidine group. Postoperative analgesia was prolonged significantly in the ropivacaine with group (429.25 $\pm 58.34 \mathrm{~min})$. Sedation scores were also higher in the dexmedetomidine group with statistically highly significant difference $(\mathrm{p}<0.001)$. Incidence of nausea, vomiting and shivering were were more in patients of ropivacaine alone group with statistically significant difference $(\mathrm{p}=0.003)$

Conclusion: Dexmedetomidine is effective adjuvant with ropivacaine for epidural block as it prolongs duration of motor block and analgesia with adequate sedation and minimal side effects.
\end{abstract}

\section{Introduction}

Epidural anesthesia is commonly used technique for providing surgical anesthesia along with but also post-operative analgesia in lower abdominal and lower limb surgeries [1]. The most sought requirement in present days infraumbilical surgeries, are early postoperative mobilization and rehabilitation with minimally associated pain and discomfort [2-4]. Many local anesthetic drugs are available for epidural anaesthesia including bupivacaine that is still popular among anaesthetists due to its desirable clinical profile, but carries inherent risk of cardiac toxicity of variable degree depending upon dosages and patient factors.

The newer amide local anesthetic ropivacaine, shares many physiochemical properties with bupivacaine but with less systemic toxicity and greater margin of safety than other local anesthetic agents of similar duration of action. The safety of ropivacaine is due to its availability in pure S- enantiomer form. It has less neurotoxic and cardiotoxic potential and preferentially blocks sensory fibres to greater degree than the motor fibers. Recent clinical data have shown that ropivacaine is safe and effective for regional anesthetic techniques. Early recovery of motor function in comparison to bupivacaine is associated with decreased venous thromboembolism and shorter hospitalization $[5,6]$.
It has always been a matter of research to find out drugs or techniques to potentiate the quality of central neuraxial blocks, a variety of drugs, such as opioids, midazolam and alpha- 2 agonists, were tried as an adjuvant with ropivacaine to prolong the duration of intraoperative and postoperative analgesia with variable results.

Alpha-2 adrenergic agonists have both analgesic and sedative properties and can be used as an effective adjuvant in epidural anesthesia [7]. Dexmedetomidine, alpha-2 agonist, is made up of medetomidine's dextrogyrous enantiomer and considered as a super selective alpha-2 adrenergic agonists prototype [8]. Dexmedetomidine is reported to have synergistic effect with ropivacaine for epidural anesthesia. As adjuvant it intensify the motor block and prolongs the duration of postoperative analgesia $[9,10]$. Studies also showed that

Correspondence to: Dr. Bhawana Rastogi, Department of Anaesthesiology \& Critical Care in NSCB Subharti Medical College, Meerut (UP), India, Tel: +918449114984; Fax: +91-0121-2439056; E-mail: dr.bhawana@gmail.com

Key words: epidural block, Ropivacaine, Adjuvant, Dexmedetomidine, Duration of analgesia, Infraumbilical surgeries

Received: March 10, 2015; Accepted: March 26, 2015; Published: March 29, 2015 
dexmedetomidine produces sedation without significant respiratory depression [11]. With this in mind, this randomized, double blinded control study was designed to evaluate the efficacy and safety of dexmedetomidine as an adjuvant to epidural $0.75 \%$ ropivacaine in patients undergoing infraumbilical surgery.

\section{Material and methods}

This prospective double blind randomized controlled study was carried out after Ethical Committee approval on 80 patients undergoing elective infraumbilical surgery under epidural anesthesia. An informed consent was obtained from each patient after fully explaining the research protocol.

Inclusion criteria were patients of ASA physical status I-II aged between 18 to 58years of either sex. Exclusion criteria were patients with physical status of ASA III or greater, uncooperative patients, previous spinal surgeries, spine deformities, local site infection and coagulation abnormalities, allergy to local anesthetics (amide group), neuromuscular diseases, patients with poorly controlled hypertension, patients with hematological disease, neurologic, psychiatric disease, severe renal or hepatic derrangement and patients with history of drug abuse.

Pre-anesthetic evaluation of the patients was performed before the surgery. Patients were administered tablet Ranitidine $150 \mathrm{mg}$ as premedicant a night before the surgery and advised for preoperative fasting as per latest ASA practice guidelines. (NPO of $6 \mathrm{hrs}$ for solids and $4 \mathrm{hrs}$ for liquids)

Randomization was done by card method. A total of 80 cards were prepared by another person who was blinded about the study. After recruitment, every patient was allowed to draw one card and grouped accordingly. Group A (Control group) received ropivacaine alone and Group B (Study group) received ropivacaine with dexmedetomidine epidurally.

In the operation theatre, intravenous line with $18 \mathrm{G}$ cannula was secured. Monitoring was done using multi parameter monitor. Baseline blood pressure (systolic, diastolic), pulse rate and arterial oxygen saturation was recorded. All patients were preloaded with $10 \mathrm{ml} / \mathrm{kg}$ of Ringer's lactate solution 15 minutes before the establishment of block. Under strict antiseptic precaution infiltration of skin with local anesthetic (2\% lignocaine), at L2/L3 level was done. Epidural space was identified with loss of resistance to air technique using 18G Tuohy's needle. An epidural catheter was advanced into epidural space for $5 \mathrm{~cm}$ and fixed. Test dose of $3 \mathrm{ml}$ of $2 \%$ lignocaine with adrenaline 1:200000 was given after negative aspiration of CSF and blood. The patients were monitored for subjective and objective signs of any inadvertent intravascular injection and subarachnoid block. Patients were asked to report any unusual subjective sensation during epidural injection and also monitored for objective signs on electrocardiogram (ECG), non invasive blood pressure (NIBP), arterial oxygen saturation $\left(\mathrm{SpO}_{2}\right)$ and respiratory rate (RR). In their absence, patient was turned to supine position. Patient was then administered either $15 \mathrm{ml} 0.75 \%$ ropivacaine $+1 \mathrm{ml}$ Normal Saline(Group I) or $15 \mathrm{ml} 0.75 \%$ ropivacaine $+0.6 \mu \mathrm{kg}^{-1}$ dexmedetomidine in $1 \mathrm{ml} \mathrm{NS}$ (group II). Drug was given at the rate of $1 \mathrm{ml} / 3 \mathrm{sec}$ through the catheter. The bilateral pin-prick method with $23 \mathrm{G}$ hypodermic needle after cleaning with spirit swab was used to evaluate and check the sensory level while a modified Bromage scale $(0=$ no block, $1=$ inability to raise extended leg, $2=$ inability to flex knee and 3 =inability to flex ankle and foot) was used to measure the motor blockade effect level at every 2 minutes interval from the time of administration of drug till 30 minutes. Intraoperatively, adequate volume status was maintained with crystalloid solutions with lactated ringer.

The following parameters were observed immediately after the administration of epidural block, every 1 minute until 5 minute and then every 5 minute interval till 15 minutes, thereafter every 15 minute upto 2 hrs and then every 30 minutes till 4 hours and then after $6 \mathrm{hr}$ and 8 hours of the block.

1. Heart rate, SBP, DBP and $\mathrm{SpO}_{2}$

2. Onset of sensory block: Time interval between the end of the administration of the epidural study drug and the beginning of tingling or numbness in the lower limbs.

3. Time to achieve complete sensory block: Time interval between the end of administration of study drug and the onset of cutaneous analgesia at T10

4. Highest dermatome level of sensory block

5. Time to complete motor blockade

6. Time to two segmental dermatomal regressions to T10: Assessed every 20 minutes after achieving highest dermatomal level of sensory analgesia.

7. Duration of sensory analgesia: Time from the administration of the drug till the time when patient demands for additional analgesia (top up).

8. Duration of motor block: Time elapsed between the administration of the drug and the regression of motor blockade till the "zero" level of the motor block according to Modified Bromage Scale

9. Sedation scores (five-point scale: 1-alert and wide awake, 2-arousable to verbal command, 3-arousable with gentle tactile stimulation, 4-arousable with vigorous shaking and 5-unarousable).

Need for supplemental sedation intraoperatively by midazolam in doses of $0.03 \mathrm{mg} / \mathrm{kg}$ as and when indicated, were recorded and tabulated for statistical analysis. Throughout the procedure patients were observed for nausea, vomiting, shivering, pain and any other discomfort or adverse event intraoperatively and managed accordingly.

\section{Statistical analysis}

A sample size of 40 in each group was estimated to give significant difference in onset of sensory and motor blockade with a power of $80 \%$ and $\alpha=0.05$. All the values were expressed as mean \pm standard deviation. Statistical comparison was performed by one way ANOVA for numerical data and chi- square test to analyze categorical data. The value of $p<0.05$ was considered as statistically significant and $p<0.001$ as highly significant.

\section{Results}

The study was successfully conducted on all 80 patients and there was no perioperative protocol deviation. All patients were cooperative with subsequent assessment of pain. The two treatment groups were comparable as regard to their demographic profile, mean duration of surgery and type of surgery (Tables 1 and 2).

It was found that addition of dexmedetomidine to ropivacaine (Group B) as an adjuvant resulted in an earlier onset of sensory block 
Table 1. Demographic profile of patients.

\begin{tabular}{|c|c|c|c|}
\hline Demographic Data & Group I & Group II & p value \\
\hline $\begin{array}{c}\text { Age (Year) } \\
\text { (Mean } \pm \text { SD) }\end{array}$ & $45.63 \pm 6.758$ & $44.25 \pm 5.410$ & 0.317 \\
\hline Sex (M:F) & $(23: 17)$ & $(24: 16)$ & 1.000 \\
\hline $\begin{array}{c}\text { Weight (kg) } \\
\text { (Mean } \pm \text { SD) }\end{array}$ & $55.92 \pm 7.852$ & $57.42 \pm 9.378$ & 0.440 \\
\hline ASA Grade (I/II) & $(15 / 25)$ & $(17 / 23)$ & 0.820 \\
\hline
\end{tabular}

$*(\mathrm{p}$-value $<0.05$ considered statistically significant).

Table 2. Mean duration and type of surgery in the two groups .

\begin{tabular}{|c|c|c|c|c|}
\hline & & Group I & Group II & p value \\
\hline \multicolumn{2}{|c|}{$\begin{array}{l}\text { Mean duration of surgery (minutes) } \\
(\text { Mean } \pm \text { SD) }\end{array}$} & $91.88 \pm 14.922$ & $89.75 \pm 14.049$ & 0.513 \\
\hline \multirow{4}{*}{$\begin{array}{l}\text { Type of } \\
\text { surgery }\end{array}$} & Inguinal Hernioplasty & 13 & 16 & 0.750 \\
\hline & TURP & 8 & 6 & 0.631 \\
\hline & Vaginal Hysterectomy & 17 & 13 & 0.587 \\
\hline & Varicose vein stripping & 2 & 5 & 0.328 \\
\hline
\end{tabular}

* (p-value $<0.05$ considered statistically significant).

Table 3. Distribution of initial and post block characteristics.

\begin{tabular}{|c|c|c|c|}
\hline Variables & Group I & Group II & p value \\
\hline $\begin{array}{c}\text { Onset of sensory block (in minutes) } \\
\text { (Mean } \pm \text { SD) }\end{array}$ & $7.00 \pm 1.198$ & $2.50 \pm 0.877$ & $0.0001^{* *}$ \\
\hline $\begin{array}{c}\text { Complete sensory block (in } \\
\text { minutes) } \\
\text { (Mean } \pm \text { SD) }\end{array}$ & $16.50 \pm 3.030$ & $15.00 \pm 2.90$ & $0.0001^{* *}$ \\
\hline $\begin{array}{c}\text { Highest dermatome level of } \\
\text { sensory block (T4:T6:T8) }\end{array}$ & $0: 19: 21$ & $28: 12: 0$ & $0.000^{* *}$ \\
\hline $\begin{array}{c}\text { Time taken for complete motor } \\
\text { block (in minutes) } \\
\text { (Mean } \pm \text { SD) }\end{array}$ & $23.90 \pm 3.565$ & $17.20 \pm 4.096$ & $0.0001^{* *}$ \\
\hline $\begin{array}{c}\text { Time to 2 segment dermatomal } \\
\text { regression till T-10 (in minutes) } \\
\text { (Mean } \pm \text { SD) }\end{array}$ & $145.25 \pm 14.320$ & $262.38 \pm 58.342$ & $0.0001^{* *}$ \\
\hline $\begin{array}{c}\text { Duration of analgesia (in minutes) } \\
\text { (Mean } \pm \text { SD) }\end{array}$ & $216.58 \pm 25.560$ & $429.25 \pm 90.444$ & $0.0001^{* *}$ \\
\hline $\begin{array}{c}\text { Duration of motor block (in } \\
\text { minutes) }\end{array}$ & $185.38 \pm 23.243$ & $362.13 \pm 72.985$ & $0.0001^{* *}$ \\
\hline (Mean \pm SD) & $0(0 \%)$ & $0(0 \%)$ & - \\
\hline Supplemental analgesia (\%) & $16(40 \%)$ & $0(0 \%)$ & $0.0001^{* *}$ \\
\hline Supplemental sedation (\%) & & & \\
\hline
\end{tabular}

$*(\mathrm{p}$-value $<0.05$ considered statistically significant $), \quad * *(\mathrm{p}$-value $<0.001 \quad$ considered statistically highly significant).

$(2.50 \pm 0.877$ minutes $)$ as compared to ropivacaine alone group $(7.00 \pm$ 1.198 minutes) ( $\mathrm{p}=0.0001$ ) (Table 3 ).

Dexmedetomidine provided a higher dermatomal spread (T4) and also helped in achieving the complete sensory anaesthetic level in a shorter period ( $15 \pm 2.90$ minutes) in comparision to ropivacaine alone with highly significant difference $(\mathrm{p}=0.0001)$. Complete motor block was also achieved earlier in dexmedetomidine group (17.20 \pm 4.10 minutes) in comparision to ropivacaine alone patients $(23.90 \pm 3.57$ minutes) and difference was highly significant ( $\mathrm{p}=0.0001)$ (Table 3 ).

Dexmedetomidine as adjuvant to ropivacine also increased the time taken for two segment dermatomal regression till T10 (262.38 \pm 58.34 minutes) and also increased the total duration of analgesia (429.25 \pm 58.34 minutes). Statistically these results were highly significant. Duration of motor block of patients in ropivacaine alone group was less (185.38 \pm 23.24 minutes) than in dexmedetomidine (362.13 \pm 72.99 minutes), was with statistically highly significant difference $(\mathrm{p}=0.0001)$ (Table 3).
Baseline heart rate were comparable $90.88 \pm 15.46$ and $96.43 \pm$ 13.76 beats/min in patients of Group A and Group B respectively, showing no significant intergroup difference $(\mathrm{p}=0.094)$. The change in heart rate between both the groups was not statistically significant till 60 minutes of study drug administration $(\mathrm{p}<0.05)$. Intra-operative time interval from 75 minutes to 8 hours showed the statistically significant difference mean of heart rate ( $\mathrm{p}$ value 0.000-0.026) (Graph 1).

Preoperatively mean systolic and diastolic blood pressure of two groups were comparable $(\mathrm{p}=0.274)$. The difference in mean SBP only at $180 \mathrm{~min}$ was found statistically significant ( $\mathrm{p}$ value 0.019 ) while the difference in mean DBP of both the groups from 5 minutes to 60 minutes was found to be statistically significant ( $p$ value $0.004-.041$ ) (Graph 2 and 3).

The baseline sedation score was comparable between the groups ( $\mathrm{p}>0.05)$. After 10 minutes of epidural drug administration, Group B

\section{PULSE (PER MINUTE)}

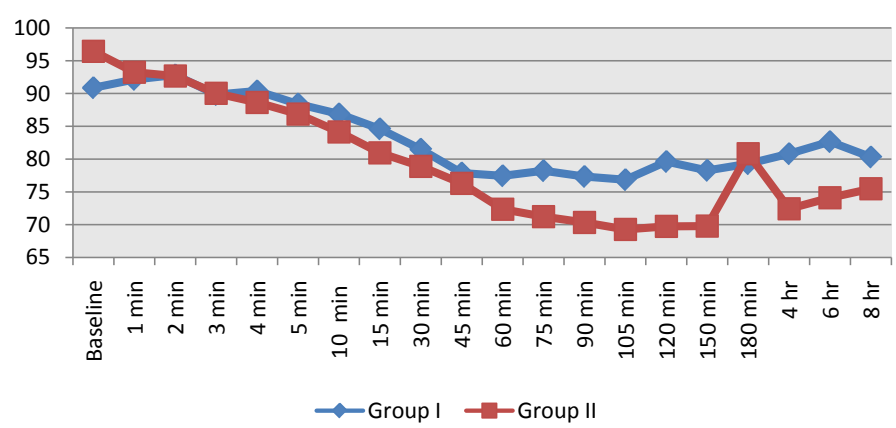

Graph 1. Changes in Pulse Rate (Per Minute).

\section{Systolic Blood Pressure (mmHg)}

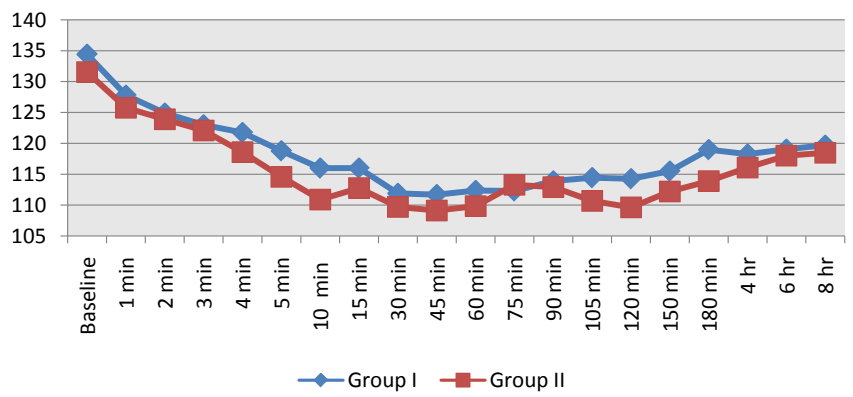

Graph 2. Comparison of the systolic blood pressure changes (mmHg).

\section{Diastolic Blood Pressure (mmHg)}

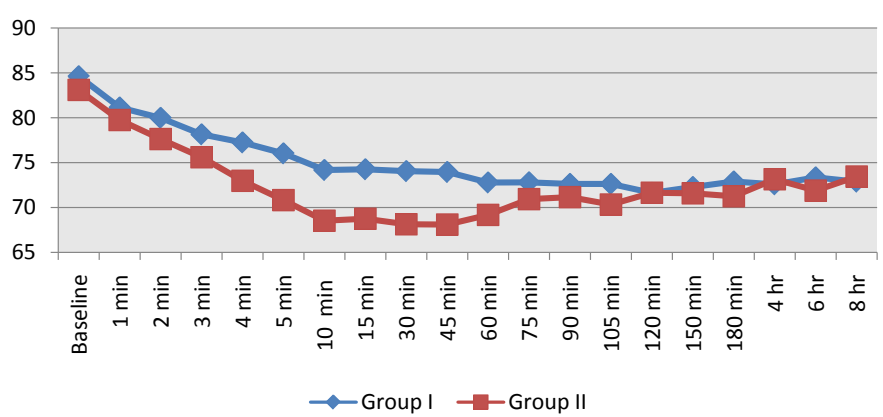

Graph 3. Comparison of the diastolic blood pressure changes ( $\mathrm{mmHg}$ ). 
showed higher sedation score than Group A. The difference of sedation score in group A and group B was statistically highly significant from 10 minutes to 180 minutes ( $\mathrm{p}$ value 0.000-0.041) (Graph 4).

Bradycardia occured in $7(17.5 \%)$ patients of group B while there was no incidence of bradycardia in group A. Hypotension occurred in $15(37.5 \%)$ patients of group B and $9(22.5 \%)$ patients of group A. The occurrence of bradycardia and hypotension in the two groups showed no statistically significant difference $(\mathrm{P}>0.05)$ (Table 4$)$. Other minor side effects like shivering, nausea, vomiting occurred in $4(10 \%)$ patients in group II and $16(40 \%)$ patients in group I. The difference in other minor side effects (like nausea, vomiting, shivering) was statistically highly significant between the two groups $(\mathrm{P}=0.0038)$ (Table 5).

\section{Discussion}

The synergistic action of epidural local anesthetics and opioids is well established [12]. The use of neuraxial opioids is associated with number of side effects, hence various other drugs including a-2 agonists, are extensively evaluated as an alternative to opioids as adjuvants to neuraxial blocks with emphasis to side effects such as respiratory depression, nausea, urinary retention and pruritis [13]. The pharmacologic properties of $\alpha-2$ agonists are extensively studied and are employed clinically to achieve analgesia, anxiolysis, hypnosis sympatholysis and sedation in regional anesthesia $[7,14]$.

In the present study, we used fixed dose and concentration of

\section{SEDATION SCORE}

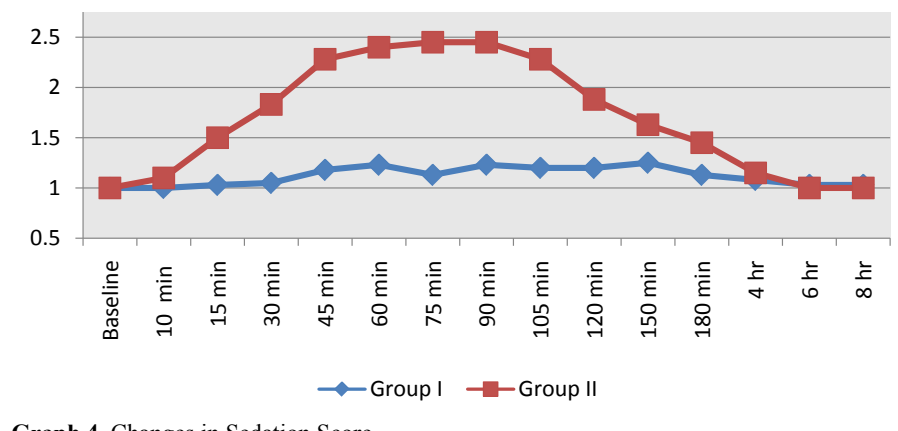

Graph 4. Changes in Sedation Score.

Table 4. Adverse effects.

\begin{tabular}{|c|c|c|c|}
\hline \multirow{2}{*}{ Adverse effect } & \multicolumn{2}{|c|}{ Group } & \multirow{2}{*}{ p value } \\
\cline { 2 - 4 } & $\begin{array}{c}\text { Group I } \\
\text { N (\%) }\end{array}$ & $\begin{array}{c}\text { Group II } \\
\text { N (\%) }\end{array}$ & \\
\hline Evidence of bradycardia & $0(0 \%)$ & $7(17.5 \%)$ & $0.012^{*}$ \\
\hline Evidence of hypotension & $9(22.5 \%)$ & $15(37.5 \%)$ & 0.222 \\
\hline Other side effects^ & $16(40 \%)$ & $4(10 \%)$ & $0.0038^{*}$ \\
\hline
\end{tabular}

$*(\mathrm{p}$-value $<0.05$ considered statistically significant $), * *(\mathrm{p}<0.001$ highly significant $) . \wedge$ Other side effects like nausea, vomiting, shivering etc.

Table 5. Incidence of other minor side effects.

\begin{tabular}{|c|c|c|c|}
\hline \multirow{2}{*}{ Other minor side effects } & \multicolumn{2}{|c|}{ Group } & \multirow{2}{*}{ P value } \\
\cline { 2 - 3 } & Group I & Group II & \\
\hline No & $24(60 \%)$ & $36(90 \%)$ & \\
\hline Vomiting & $3(7.5 \%)$ & $4(10 \%)$ & \multirow{2}{*}{$0.001 * *$} \\
\hline Nausea & $1(2.5 \%)$ & $0(0 \%)$ & \\
\hline Shivering & $12(30 \%)$ & $0(0 \%)$ & \\
\hline Total & $\mathbf{4 0}$ & $\mathbf{4 0}$ & \\
\hline
\end{tabular}

$*(p$-value $<0.05$ considered statistically significant $), * *(p<0.001$ highly significant $)$. ropivacaine i.e. $15 \mathrm{ml}$ of $0.75 \%$ ropivacaine in both the groups as the volume of the study drug because the influence of height and weight on the spread of epidural block is very little, and usually not clinically relevant unless considering the extremes of the spectrum [15].

Earlier onset of sensory and motor block, less time for onset of complete sensory and motor block, and prolonged analgesia and duration of motor block can be explained by the fact that epidural dexmedetomidine has greater selectivity for alpha2 receptors with greater lipid solubility so easily penetrated in the meninges $[16,17]$. They also cause augmentation of local anesthetic effects as they cause hyperpolarisation of nerve tissues by altering transmembrane potential and ion conductance at locus coeruleus in the brainstem $[18,19]$. The increase in analgesic action of local anesthetics by use of alpha 2 agonists in the epidural space may be related to the reduction of the systemic absorption of the local anesthetic effect caused by local vasoconstrictor subtypes mediated by the $\mathrm{C} 2$ in smooth muscle and venous epidural plexus $[20,21]$.

The analgesic effect of dexmedetomidine possibly produced by the stimulation of spinal cord at the dorsal root neuron level, where alpha-2 agonists inhibit the release of substance $\mathrm{P}$ in the nociceptive pathway and also inhibit the release of norepinephrine, at the nerve endings $[22,23]$. The spinal mechanism is considered to be mainly responsible for the analgesic effects though there is some evidence of both the supraspinal and peripheral sites of action of Dexmedetomidine [24].

Bajwa et al. in their study compared dexmedetomidine and clonidine as adjuvant to ropivacaine for epidural and concluded that dexmedetomidine group has faster onset of sensory analgesia till $\mathrm{T}_{10}$ and duration of motor block was also longer. In their another study they compared dexmedetomidine with fentanyl as adjuvant to ropivacaine in epidural and summarized that dexmedetomidine group has higher maximum sensory block dermatome $\mathrm{T}_{4-6}$, and showed prolonged two dermatome regression time and duration of analgesia $[25,26]$.

The clinical study by Giri and Iqbal, showed that addition of dexmedetomidine to ropivacaine as an adjuvant resulted in an earlier onset (8.52 \pm 2.36 minutes) of sensory analgesia at T10 as compared to the ropivacaine alone $(9.72 \pm 3.44$ minutes). They also concluded that time taken to two segmental dermatomal regression was slow with dexmedetomidine $(136.46 \pm 8.12$ minutes $)$ than ropivacaine alone (128 minutes). Duration of analgesia $(342$ minutes $(\mathrm{p}<0.05)$ and motor block ( $246.72 \pm 30.46$ minutes) was also comparatively longer in dexmedetomidine group [27]. The results of these studies are in accordance to present study.

In the present study negative chronotropic effect was exhibited by dexmedetomidine approximately 60 minutes after the epidural injection of the drugs. The decrease in HR caused by $\alpha-2$ agonist can again be explained on the basis of their central action whereby they decrease sympathetic outflow and nor-epinephrine release $[24,28,29]$.

However, in a study conducted by Saravia et al., there was no statistically significant difference in the perioperative heart rate. They compared epidural block characteristics of two groups of 20 patients each and found no significant difference in the onset time of sensory block and time taken to achieve sensory block till T10 between the two groups $(\mathrm{p}>0.05)$. This difference in their results could probably due to small sample size $(n=20)$ of the study. They also found that the duration of analgesia was significantly higher in group receiving dexmedetomidine than control group and the duration of motor blockade was significantly higher in the dexmedetomidine group, averaging 30\% higher than that observed in the control group [10]. 
Sedative effect of dexmedetomidine is probably mediated by the activation of presynaptic alpha- 2 adrenoreceptors in the locus coeruleus, leading to inhibition of release of norepinephrine [30] along with it inhibition of adenylate cyclase may lead to hypnotic response [31]. The present study showed that dexmedetomidine group has higher sedation scores. Saravia et al. studied bispectral index 30 minutes after the execution of anesthesia and noted that bispectral values were lower and patients were more sedated in dexmedetomidine group than in the control group $(\mathrm{p}<0.05)[10]$.

Dexmedetomidine does not decrease gut motility, hence it prevents intraoperative and postoperative nausea and vomiting [32]. As far as $a-2$ agonists are concerned, the respiratory depression is not a known feature of this group of drugs. Lack of respiratory depression in the patients who were administered dexmedetomidine was one of the most remarkable findings and the evidence was similar to the earlier studies where researchers have found complete absence of clinically detectable respiratory depression in the previous multiple human studies [33-35].

\section{Conclusion}

We conclude that epidural dexmedetomidine as adjuvant to ropivacaine produces synergistic effects with earlier onset time of sensory block, earlier achievement of complete sensory and motor blockade, prolonged sensory and motor blockade and good intraoperative sedation. Dexmedetomidine in a dose of 0.6 microgram $\mathrm{kg}^{-1}$ is a safe and effective adjuvant to ropivacaine in epidural blockade for infraumbilical surgeries.

Financial support: Subharti Medical College, Meerut, U.P.

\section{References}

1. Schultz AM, Werba A, Ulbing S, Gollmann G, Lehofer F (1997) Peri-operative thoracic epidural analgesia for thoracotomy. Eur J Anaesthesiol 14: 600-603. [Crossref]

2. Kehlet H (1999) Acute pain control and accelerated postoperative surgical recovery. Surg Clin North Am 79: 431-443. [Crossref]

3. Bradshaw BG, Liu SS, Thirlby RC (1998) Standardized perioperative care protocols and reduced length of stay after colon surgery. J Am Coll Surg 186: 501-506. [Crossref]

4. Kehlet H, Mogensen T (1999) Hospital stay of 2 days after open sigmoidectomy with a multimodal rehabilitation programme. Br J Surg 86: 227-230. [Crossref]

5. Stienstra R (2003) The place of ropivacaine in anesthesia. Acta Anaesthesiol Belg 54: 141-148. [Crossref]

6. Agarwal A, Verma RK, Srivastava S (2010) Ropivacaine: The latest local anesthetic in the Indian Market. $J$ Anesth Clin Pharmacol 26: 223-228.

7. Vieira AM, Schnaider TB, Brandão AC, Pereira FA, Costa ED, et al. (2004) Epidural clonidine or dexmedetomidine for post-cholecystectomy analgesia and sedation. Rev Bras Anestesiol 54: 473-478. [Crossref]

8. Halaszynski TM (2012) Dexmedetomidine: A look at a promising new avenue of use. Saudi J Anaesth 6: 104-106. [Crossref]

9. Salgado PF, Sabbag AT, Silva PC, Brienze SL, Dalto HP, et al. (2008) Synergistic effect between dexmedetomidine and $0.75 \%$ ropivacaine in epidural anesthesia. Rev Assoc Med Bras 54: 110-115. [Crossref]

10. Salgado PF, Nascimento P, Modolo NSP (2005) Adding dexmedetomidine to ropivacaine $0.75 \%$ for epidural anaesthesia. Does it improve the quality of anesthesia? Anesthesiology 103: A974.

11. Lopez SAO, Sanchez KAM, Bernal CEH (2008) Epidural dexmedetomidine in regional anaesthesia to reduce anxiety. Revista Mexicana de Anestesiologia 31: 271-277.

12. Soto RG, Fu ES (2003) Acute pain management for patients undergoing thoracotomy. Ann Thorac Surg 75: 1349-1357. [Crossref]

13. Arain SR, Ruehlow RM, Uhrich TD, Ebert TJ (2004) The efficacy of dexmedetomidine versus morphine for postoperative analgesia after major inpatient surgery. Anesth Analg 98: 153-158, table of contents. [Crossref]
14. Gabriel JS, Gordin V (2001) Alpha 2 agonists in regional anesthesia and analgesia. Curr Opin Anaesthesiol 14: 751-753. [Crossref]

15. Duggan J, Bowler GM, McClure JH, Wildsmith JA (1988) Extradural block with bupivacaine: influence of dose, volume, concentration and patient characteristics. $\mathrm{Br} J$ Anaesth 61: 324-331. [Crossref]

16. De Wolf AM, Fragen RJ, Avram MJ, Fitzgerald PC, Rahimi-Danesh F (2001) The pharmacokinetics of dexmedetomidine in volunteers with severe renal impairment. Anesth Analg 93: 1205-1209. [Crossref]

17. Asano T, Dohi S, Ohta S, Shimonaka H, Iida H (2000) Antinociception by epidural and systemic alpha(2)-adrenoceptor agonists and their binding affinity in rat spinal cord and brain. Anesth Analg 90: 400-407. [Crossref]

18. Fukushima K, Nishimi Y, Mori K (1997) The effect of epidural administered dexmedetomidine on central and peripheral nervous system in man. Anesth Analg 84: S292

19. Correa-Sales C, Rabin BC, Maze M (1992) A hypnotic response to dexmedetomidine, an alpha 2 agonist, is mediated in the locus coeruleus in rats. Anesthesiology 76: 948952. [Crossref]

20. Nishikawa T, Dohi S (1990) Clinical evaluation of clonidine added to lidocaine solution for epidural anesthesia. Anesthesiology 73: 853-859. [Crossref]

21. Eisenach JC, De Kock M, Klimscha W (1996) alpha(2)-adrenergic agonists for regional anesthesia. A clinical review of clonidine (1984-1995). Anesthesiology 85: 655-674. [Crossref]

22. Kuraishi Y, Hirota N, Sato Y, Kaneko S, Satoh M, et al. (1985) Noradrenergic inhibition of the release of substance $\mathrm{P}$ from the primary afferents in the rabbit spinal dorsal horn. Brain Res 359: 177-182. [Crossref]

23. Jaakola ML, Salonen M, Lehtinen R, Scheinin H (1991) The analgesic action of dexmedetomidine--a novel alpha 2 -adrenoceptor agonist--in healthy volunteers. Pain 46: 281-285. [Crossref]

24. Bhana N, Goa KL, McClellan KJ (2000) Dexmedetomidine. Drugs 59: 263-268 [Crossref]

25. Bajwa SJ, Bajwa SK, Kaur J (2010) Comparison of epidural ropivacaine and ropivacaine clonidine combination for elective cesarean sections. Saudi J Anaesth 4 : 47-54. [Crossref]

26. Bajwa SJ, Arora V, Kaur J, Singh A, Parmar SS (2011) Comparative evaluation of dexmedetomidine and fentanyl for epidural analgesia in lower limb orthopedic surgeries. Saudi J Anaesth 5: 365-370. [Crossref]

27. Giri RS, Iqbal MM (2013) A randomized clinical trial comparing the efficacy and safety of ropivacaine $0.75 \%$ alone and in combination with dexmedetomidine for lower abdominal and lower limb surgeries. V Care for Life Sciences Journal 3: 55-56.

28. Kalso EA, Pöyhiä R, Rosenberg PH (1991) Spinal antinociception by dexmedetomidine, a highly selective alpha 2-adrenergic agonist. Pharmacol Toxicol 68: 140-143. [Crossref]

29. Talke P, Richardson CA, Scheinin M, Fisher DM (1997) Postoperative pharmacokinetics and sympatholytic effects of dexmedetomidine. Anesth Analg 85: 1136-1142. [Crossref]

30. Maze M, Regan JW (1991) Role of signal transduction in anesthetic action. Alpha 2 adrenergic agonists. Ann N Y Acad Sci 625: 409-422. [Crossref]

31. Memis D, Turan A, Karamanlioglu B, Pamukcu Z, Kurt I (2004) Adding dexmedetomidine to lidocaine for intravenous regional anesthesia. Anesth Analg 98 835-840. [Crossref]

32. Panda A (2014) Effectiveness of Dexmedetomidine infusion in reducing postoperative nausea and vomiting after laparoscopic surgery. Transworld Medical Journal 2: 83-89.

33. Venn RM, Hell J, Grounds RM (2000) Respiratory effects of dexmedetomidine in the surgical patient requiring intensive care. Crit Care 4: 302-308. [Crossref]

34. Venn RM, Bradshaw CJ, Spencer R, Brealey D, Caudwell E, et al. (1999) Preliminary UK experience of dexmedetomidine, a novel agent for postoperative sedation in the intensive care unit. Anaesthesia 54: 1136-1142. [Crossref]

35. Hall JE, Uhrich TD, Barney JA, Arain SR, Ebert TJ (2000) Sedative, amnestic, and analgesic properties of small-dose dexmedetomidine infusions. Anesth Analg 90: 699705. [Crossref]

Copyright: (C2015 Rastogi B. This is an open-access article distributed under the terms of the Creative Commons Attribution License, which permits unrestricted use, distribution, and reproduction in any medium, provided the original author and source are credited. 